\title{
Finite Elements Analysis of PLA 3D-printed Elements and Shape Optimization
}

\author{
P. Żur ${ }^{1}$, A. Kołodziej ${ }^{1}$ and A. Baier ${ }^{1}$ \\ ${ }^{1}$ Silesian University of Technology, Faculty of Mechanical Engineering, \\ Konarskiego 18a, 44-100 Gliwice, Poland.
}

\section{ARTICLE INFO}

Keywords:

\begin{abstract}
The paper presents the Finite Element Method (FEM) analysis of 3Dprinted parts and further shape optimization. Information obtained from the static bending test allowed to carry out the FEM analysis in Siemens NX software with Nastran module. The first part of the research was a comparative analysis of FEM analysis of a single specimen with real-life data collected for polylactide (PLA) specimens made in Fused Deposition Modelling (FDM) technology. Next step was FEM analysis of a PLA brake lever which is used in Silesian Greenpower electric vehicle. Silesian Greenpower team uses 3D-printing for rapid prototyping and manufacturing of customized parts of almost any shape for their car. Purpose of the Finite Element Analysis was shape optimization of the lever in order to ensure adequate safety and ergonomics of use. The strains during its operation should not exceed the maximum permissible for the material used. As this is a key element of safety, a safety factor of level 3 has been adopted. FEM analysis contributed to weight reduction and shape optimization to withstand applied forces.
\end{abstract}

\section{Introduction}

Simulation is currently an integral part of design and manufacturing. Requirements set for manufacturers forces them to produce pieces that are lighter, more durable, easier to produce, cheaper and shape-optimised. Finite Element Analysis is a key simulation method nowadays. FEA works by breaking down a large structure, with high degrees of physical complexities and mathematical discontinuities, into smaller, more manageable sections. Each section represents the material properties of its local domain. By slicing the structure into smaller and smaller sections, the simulator gains an understanding of how the larger structure will respond to external or internal stimuli.

FEM has been developed in the 1960s, but lack of computer memory capable of billions of calculations made it wait for use until now. It has been widely used in solving structural, mechanical, heat transfer, and fluid dynamics problems as well as problems of other disciplines. The advancement in computer technology enables us to solve an even larger system of equations, to formulate and assemble the discrete approximation, and to display the results quickly and 
conveniently. This has also helped the finite element method become a powerful tool in modern mechanical engineering and manufacturing.

Modern programs of the CAD/CAE class have great potential for carrying out advanced stress analysis, fatigue analysis or kinematic and dynamic ones. Silesian Greenpower team uses FEM analysis not only for manufacturing of customized parts, but also for aerodynamic simulation (Fig. 1). On a basis of results of analysis of existence of Kammback aerodynamic effect innovative car body were modelled.

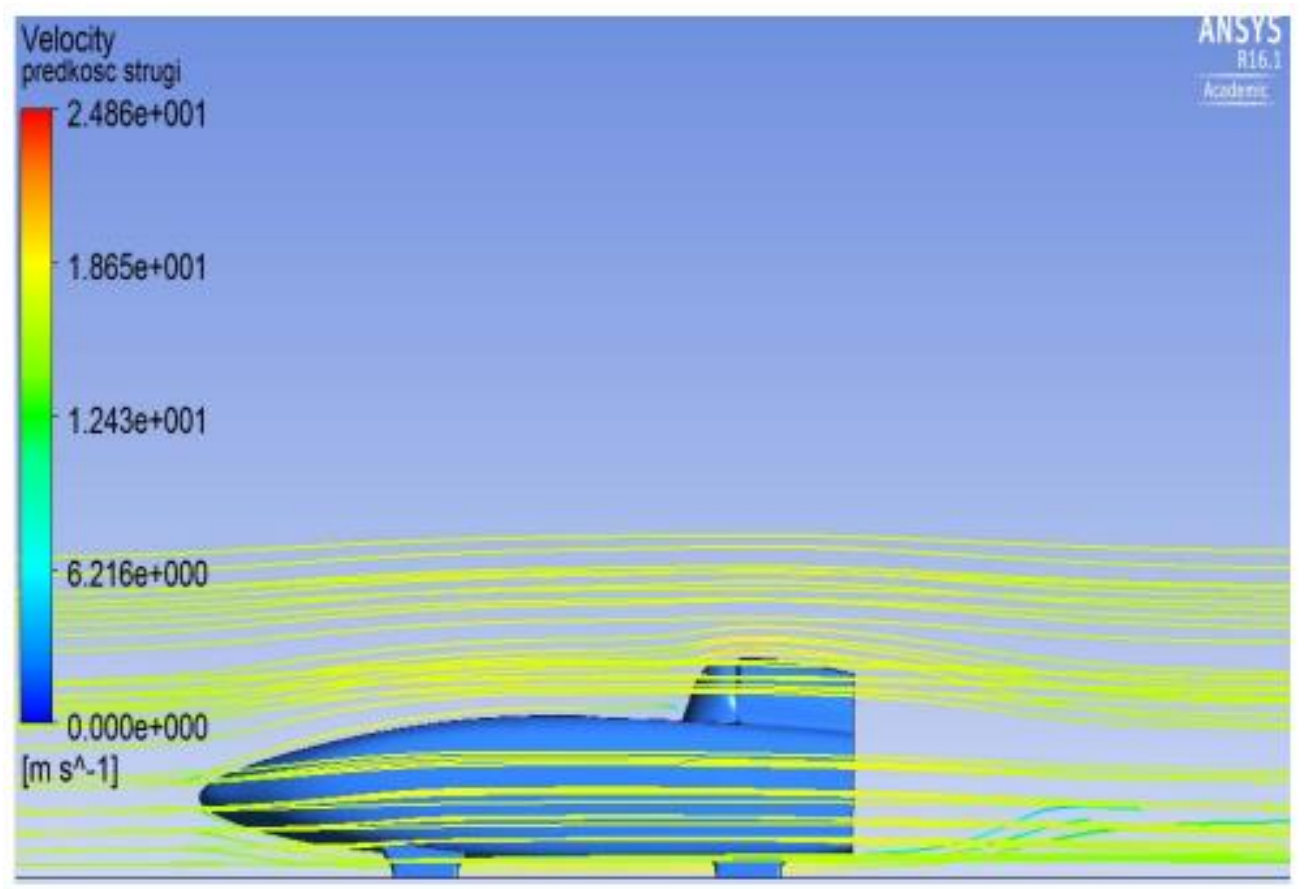

Fig. 1. Aerodynamic simulation test carried out by Silesian Greenpower team.

\section{Test objective}

\subsection{FEM Simulation of Static Bending Test}

The first part of the research was finite element analysis of a flexural stress and strain in a specimen. FEA has been carried out in Siemens NX software with Nastran module. The size and dimensions of the sample were as specified in PN-EN ISO 178:2011 International Standard: 80 $\mathrm{mm}$ length, $4 \mathrm{~mm}$ height and $10 \mathrm{~mm}$ width. Necessary boundary conditions have been set according to the standard spacing between supports is described with a formula:

$$
L=(16 \pm 1) * h
$$

Where:

$\mathrm{L}$ - spacing between supports

$\mathrm{h}$ - height of the sample

Material properties for the inspected sample have been set according to results obtained in reallife static bending test shown in Table 1. The purpose of the FEM analysis was to determine the maximum force at the stress which will not exceed the maximum acceptable for the selected material and comparative analysis of obtained FEA results with real-life ones. 
Table 1. Physical and mechanical properties of static bending test PLA samples.

\begin{tabular}{lll}
\hline Material property & Value & Units \\
\hline Density $(\rho)$ & 1.24 & $\mathrm{~g} / \mathrm{cm}^{3}$ \\
\hline Elastic modulus $(E)$ & 3149 & $\mathrm{MPa}$ \\
\hline Shear modulus $(G)$ & 1287 & $\mathrm{MPa}$ \\
\hline Poisson's ratio $(v)$ & 0.36 & - \\
\hline Yield strength $\left(\sigma_{y}\right)$ & 77 & $\mathrm{MPa}$ \\
\hline Flexural strength $\left(\tau_{z}\right)$ & 88 & $\mathrm{MPa}$ \\
\hline
\end{tabular}

The Finite Element Analysis have been carried out in Siemens NX with Nastran module. The stress and deformation results have been presented respectively in Fig. 2 and Fig. 3.

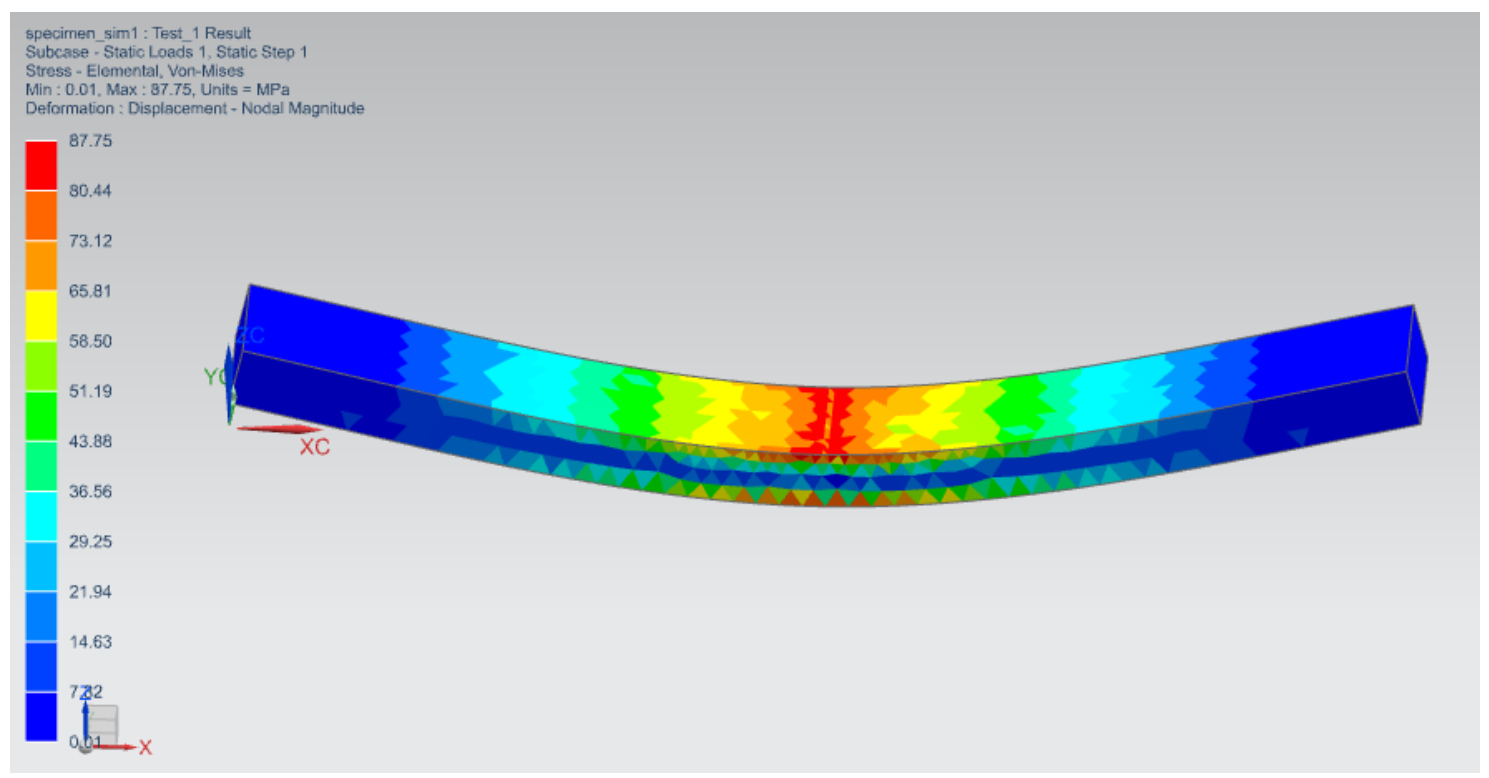

Fig. 2. Stress results of the FEM analysis. 


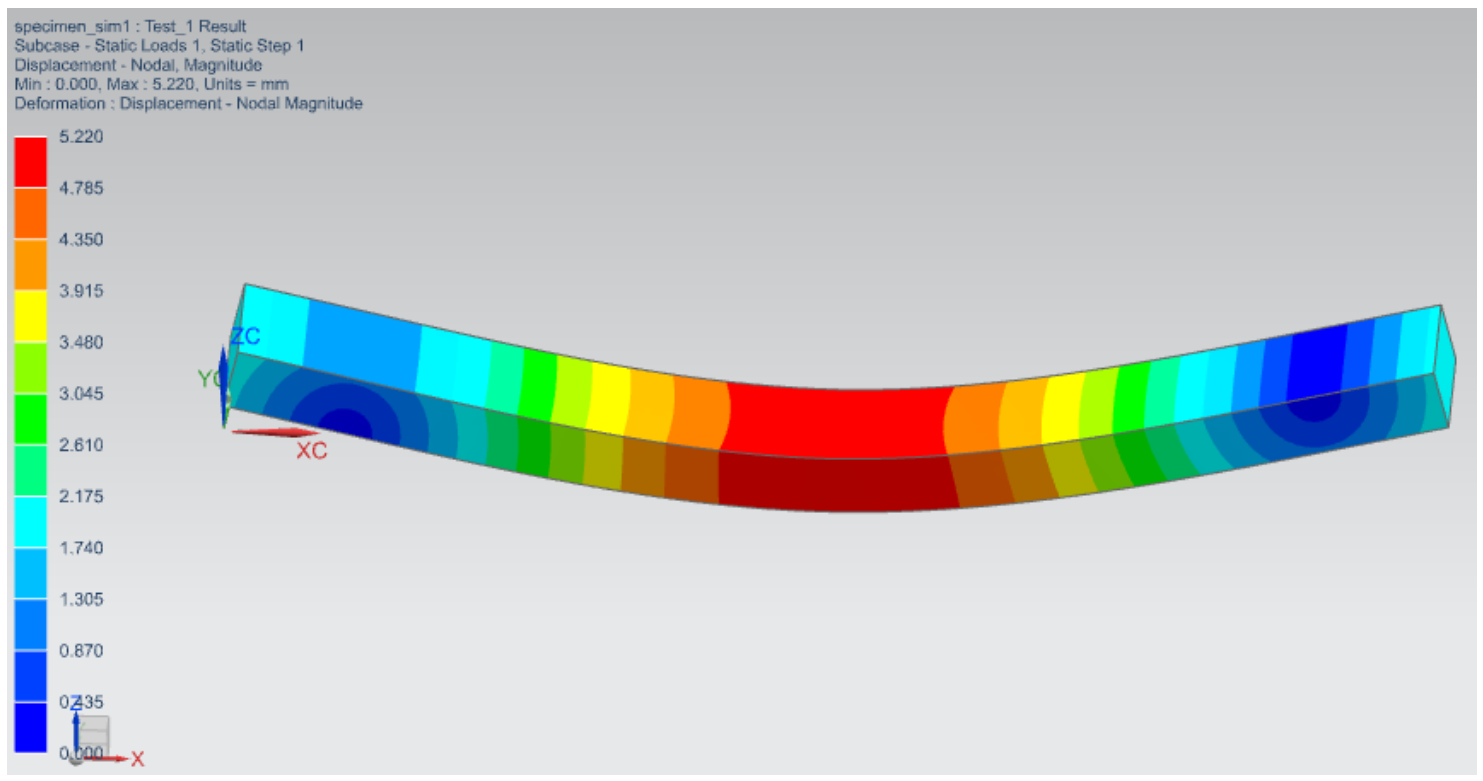

Fig. 3. Displacement results of the FEM analysis.

The maximum stress obtained in the simulation was $87,75 \mathrm{MPa}$ at $157 \mathrm{~N}$, while real-life test gave results of $89,27 \mathrm{MPa}$ at $156,32 \mathrm{~N}$ (Table 2). Based on this analysis for a single specimen, which can be compared to the research of real static bending test it can be seen, that these values are very similar, which confirms the result obtained in real-life test and another way round. The difference In obtained stress values is just $1,7 \%$.

Table 2. Comparison of real-life results with FEM analysis.

\begin{tabular}{llll}
\hline & Displacement [mm] & Force [N] & Stress [MPa] \\
\hline Flexural test & 6,51 & 156,32 & 89,27 \\
\hline FEM - Siemens NX & 5,22 & 157 & 87,75 \\
\hline
\end{tabular}

The slight difference in displacement may have been due to a simplification in the selection of constraint types in the programme.

\subsection{FEM Analysis of Brake Lever and Shape Optimization}

Next step of the research was Finite Element Analysis of a brake lever used in Silesian Greenpower vehicle. Necessary safety factor has been set at level of 3 . The simulation has been carried out in the same software and with the same material properties set as before. Stress results of the simulation have been shown in Fig. 4. 


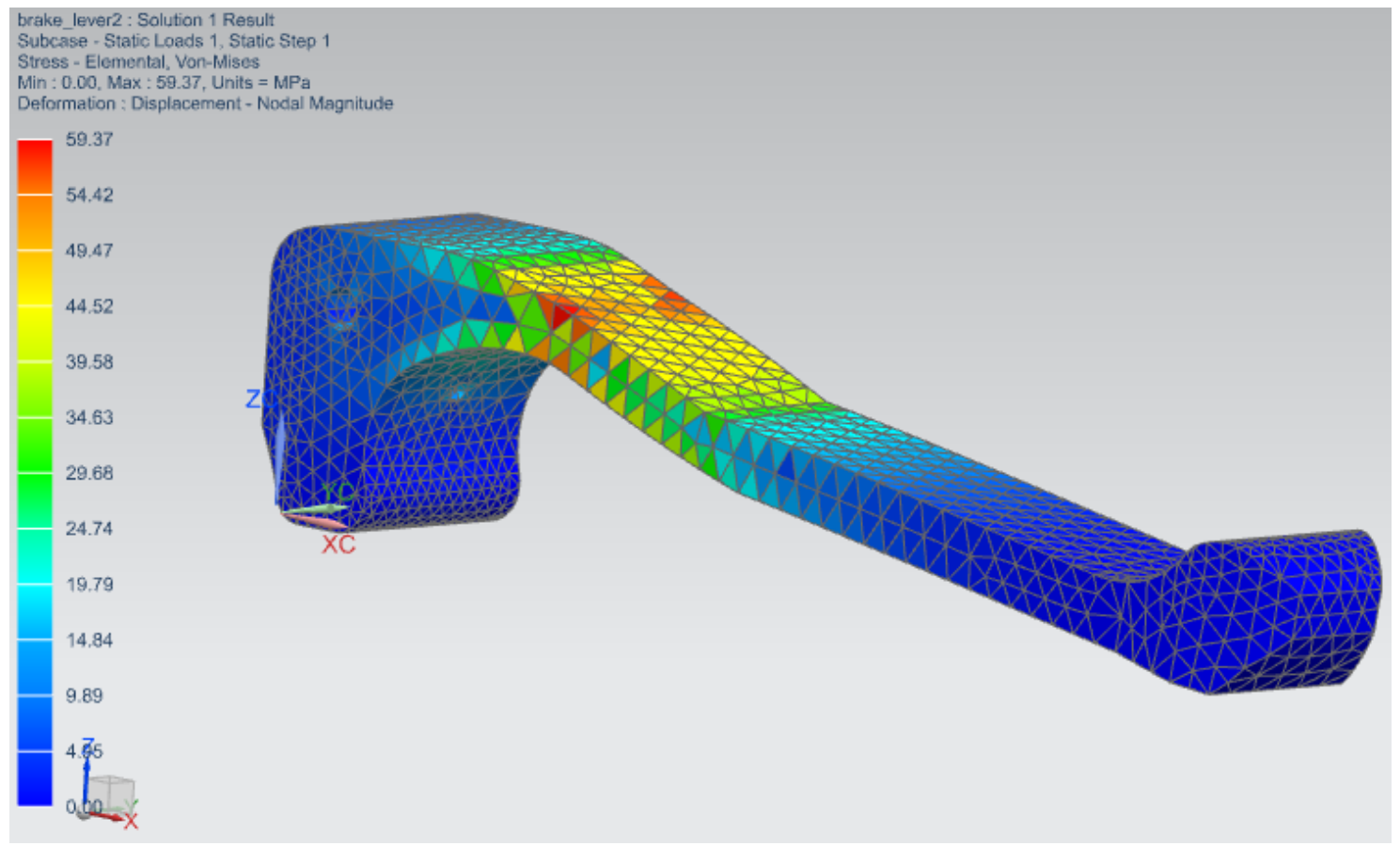

Fig. 4. Stress results of the FEM simulation of brake lever before optimization.

It can be seen that the maximum stress value is $59,37 \mathrm{MPa}$ at $125 \mathrm{~N}$ applied force. The element has been subjected to shape optimization - the part where the stress is the highest has been thickened. After optimization, the stress was just 14,37 MPa at the same force applied (Fig. 5). Stress value in the critical point of the lever has been reduced by $75,8 \%$.

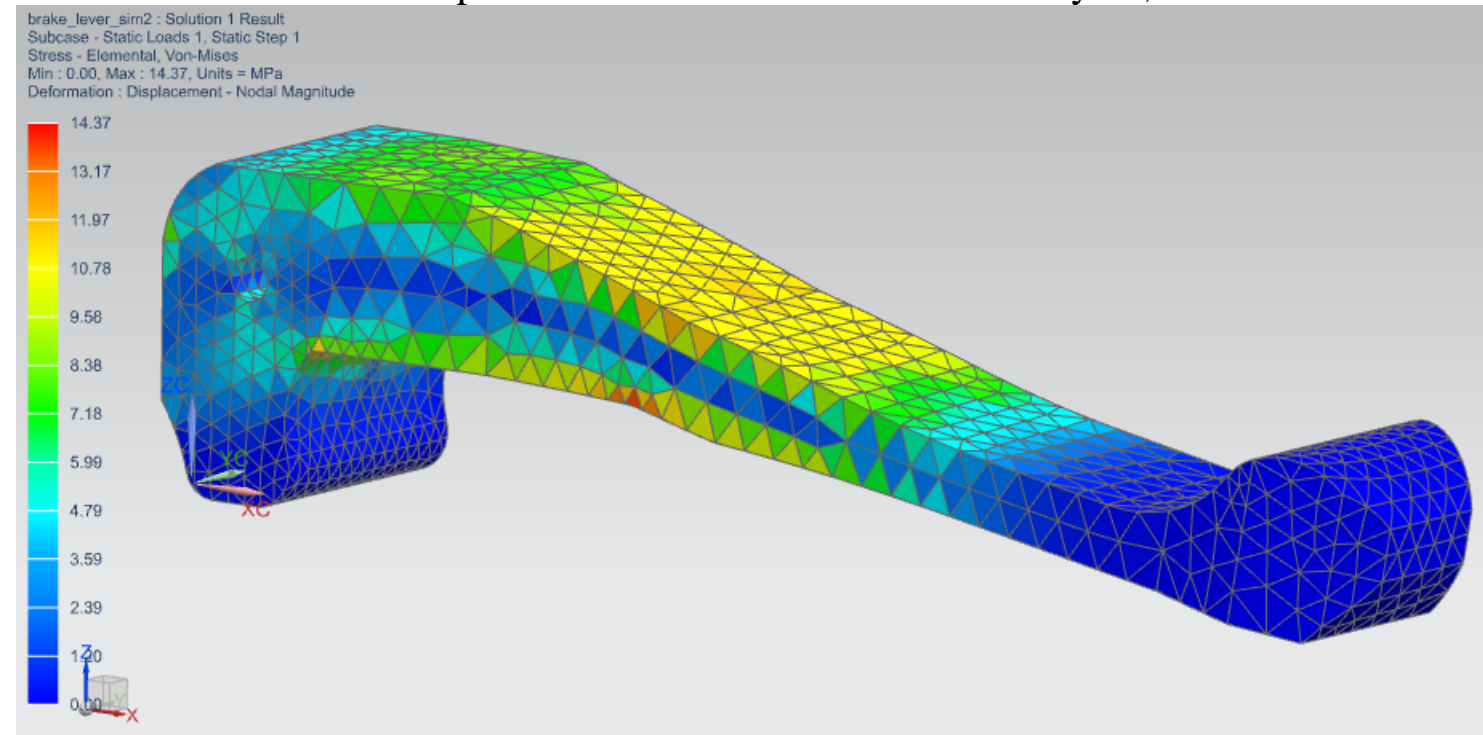

Fig. 5. Stress results of the FEM simulation of brake lever after optimization.

Further, different infill pattern has been used in order to reduce the weight of the element. It has been changed from full infill with layer orientation $45^{\circ}$ to honeycomb infill pattern with $25 \%$ density (Fig. 6). 


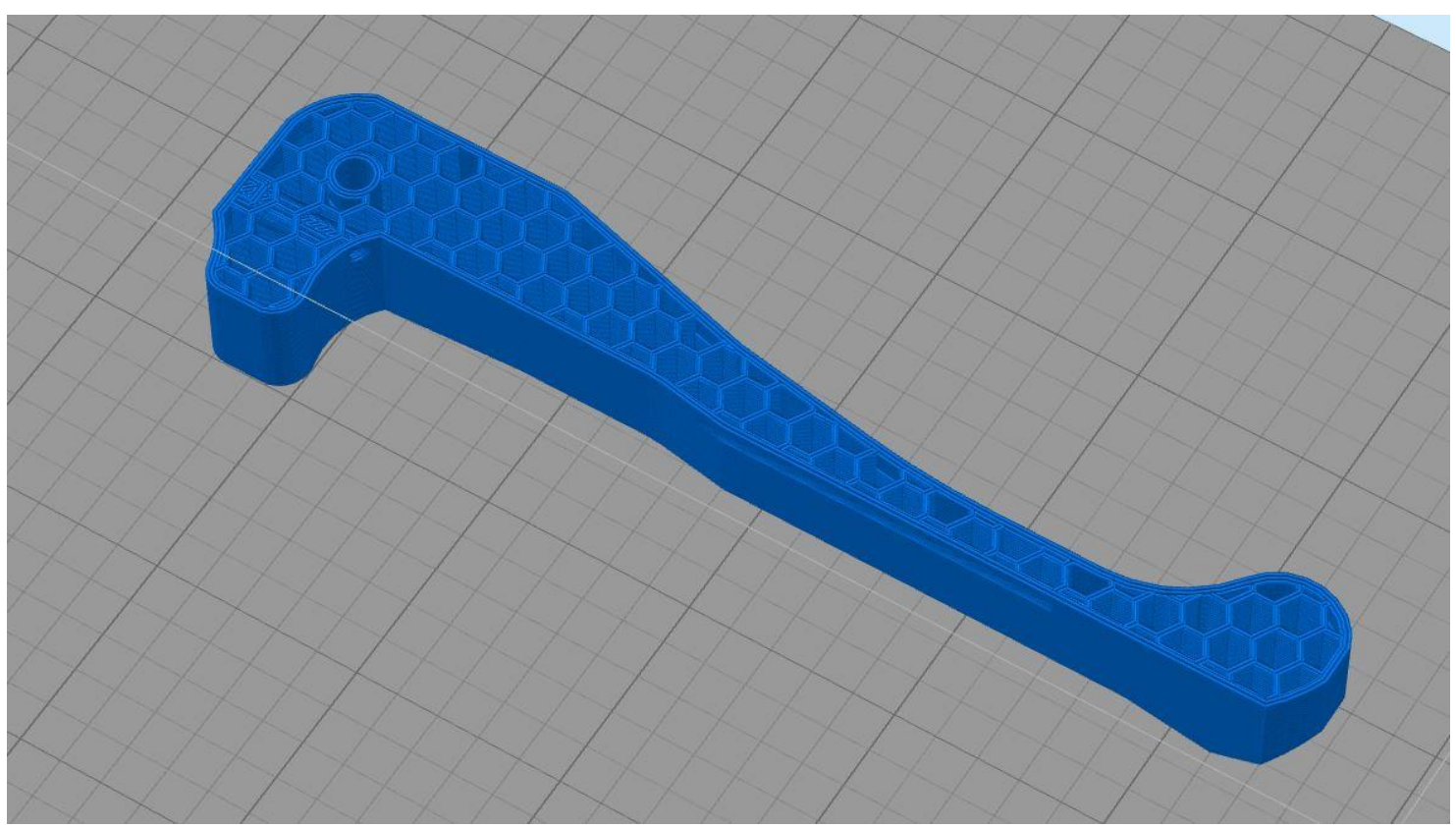

Fig. 6. Change of the infill pattern $-25 \%$ honeycomb.

After optimizing the shape and changing the infill type - different infill pattern (honeycomb 25\%) has reduced the weight of an element from 36,79 $\mathrm{g}$ to $18,24 \mathrm{~g}$ (Table 3), which means weight reduction by $50,42 \%$ compared to full infill after optimization, and by $18,24 \%$ compared to the weight of the element before optimization. This feature allows to reduce material cost by $50,65 \%$ compared to optimized part with full infill, and by $38,96 \%$ compared to non-optimized element. Table 3. Influence of shape and structure optimization of manufacturing process.

\begin{tabular}{|c|c|c|c|}
\hline $\begin{array}{l}\text { Infill } \\
\text { percentage }\end{array}$ & $\begin{array}{l}100 \%-\text { before } \\
\text { optimization }\end{array}$ & $\begin{array}{l}100 \%\left(45^{\circ}\right)-\text { after } \\
\text { optimization }\end{array}$ & $\begin{array}{l}\text { Honeycomb }(25 \%) \text { - after } \\
\text { optimization }\end{array}$ \\
\hline Build time & 68 minutes & 95 minutes & 83 minutes \\
\hline Plastic weight & $22,37 \mathrm{~g}$ & $36,79 \mathrm{~g}$ & $18,24 \mathrm{~g}$ \\
\hline Material cost & $0,47 €$ & $0,77 €$ & $0,38 €$ \\
\hline
\end{tabular}

Optimization of the brake lever in the Siemens NX program with the use of the Pre / Post module enabled the manufacturing of the element for the Silesian Greenpower car while ensuring adequate safety and ergonomics of use. After the simulation, the shape of the lever was selected so that it would be able to transfer loads during use.

Additionally, by following the results obtained during the static bending test, the printing pattern of the above-mentioned element was changed. By choosing a honeycomb infill with a density of $25 \%$ (maximum bending strength of $47 \mathrm{MPa}$ ), the mass of the element was reduced while maintaining the appropriate safety factor assumed at the beginning of the tests.

The slight increase in print time due to the number of elements needed does not matter for the manufacturing process.

\section{Conclusions}

1. FEM analysis of a static bending test gives very similar results to real-life bending test - the difference in stress value is just $1,7 \%$. 
2. Shape optimization allowed to reduce stress value in the inspected element from 59,37 $\mathrm{MPa}$ to $14,37 \mathrm{MPa}$ - that means that stress value has been reduced by $75,8 \%$.

3. Different infill pattern and its density (honeycomb 25\%) allow reducing the weight of the element by more than $50 \%$ compared to full infill optimized part.

4. By using infill pattern with lower density but the same strength, the cost of material has been reduced by over $50 \%$.

\section{References}

Bathe, K. J. (2006). Finite element procedures. Klaus-Jurgen Bathe.

math.nist.gov [retrieved 13-11-2018]

PN-EN ISO 178:2011 Plastics - determination of flexural properties

Torres, J., Cotelo, J., Karl, J., \& Gordon, A. P. (2015). Mechanical property optimization of FDM PLA in shear with multiple objectives. Jom, 67(5), 1183-1193.

matweb.com [retrieved 03-11-2018]

manortool.com [retrieved 13-11-2018]

Baier, A., Grabowski, Ł., Stebel, Ł., Komander, M., Konopka, P., Kołodziej, A., \& Żur, P. (2018).

Numeric analysis of airflow around the body of the Silesian Greenpower vehicle. In MATEC Web of Conferences (Vol. 178, p. 05014). EDP Sciences.

Ociepka, P., \& Herbus, K. (2015). Strength analysis of parallel robot components in PLM Siemens NX 8.5 program. In IOP Conference Series: Materials Science and Engineering (Vol. 95, No. 1, p. 012101). IOP Publishing.

Grabowski, L., Baier, A., Buchacz, A., Majzner, M., \& Sobek, M. (2015). Application of CAD/CAE class systems to aerodynamic analysis of electric race cars. In IOP Conference Series: Materials Science and Engineering (Vol. 95, No. 1, p. 012044). IOP Publishing.

Segerlind, L. J. (1976). Applied finite element analysis (Vol. 316). New York: Wiley. 